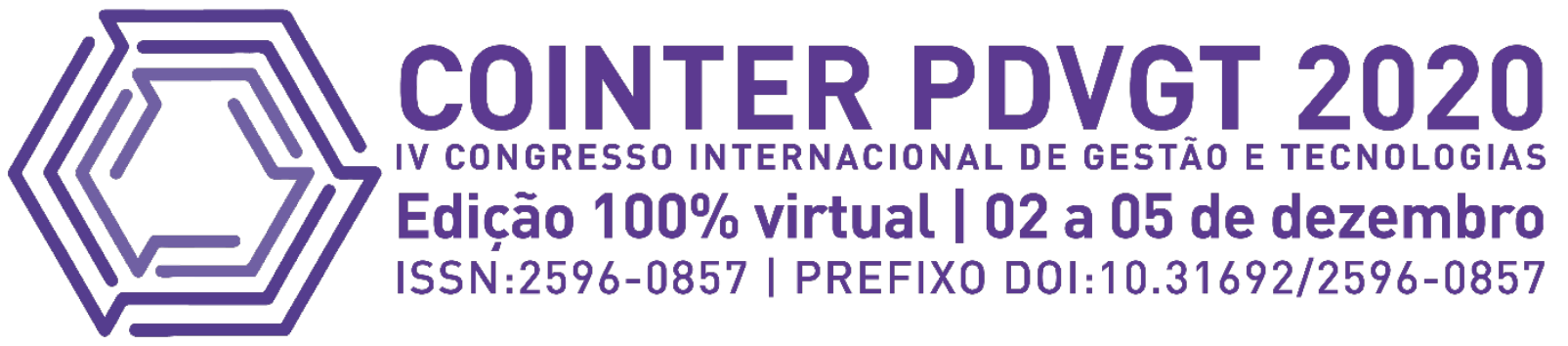

\title{
A CONTRIBUIÇÃO DO EMPREENDEDORISMO NA EDUCAÇÃO PARA JOVENS COMO PROPOSTA DE FORMAÇÃO E DESENVOLVIMENTO DE HABILIDADES E LIDERANÇA
}

\section{LA CONTRIBUCIÓN DEL EMPRENDIMIENTO EN LA EDUCACIÓN DE LOS JÓVENES COMO PROPUESTA DE FORMACIÓN Y DESARROLLO DE COMPETENCIAS}

\section{THE CONTRIBUTION OF ENTREPRENEURSHIP IN EDUCATION FOR YOUNG PEOPLE AS A PROPOSAL FOR TRAINING AND DEVELOPING SKILLS}

\author{
Apresentação: Comunicação Oral
}

Max Jefferson da Silva Nascimento; Larissa Grasielle Nazário de Melo${ }^{1}$; Everton Medeiros Bezerra $^{2}$; Edísio Raimundo da Silva ${ }^{3}$; Erick Viana da Silva ${ }^{4}$

DOI::https://doi.org/10.31692/2596-0857.IVCOINTERPDVGT.0132

\begin{abstract}
RESUMO
Este artigo teve como objetivo principal discutir o empreendedorismo através de sua aplicação na educação. Foi realizada uma revisão de literatura abordando os principais conceitos e educação empreendedora e discutido o impacto que pode gerar através habilidades gerar em sala de aula. A pesquisa desenvolvida abordou. A educação empreendedora propõe o estímulo a formação crítica dos estudantes motivados por discentes. Desenvolvendo nos mesmos habilidades e abrindo caminhos para mundo do negócio. A importância de se estudar o empreendedorismo vai além de se ter estratégias que visam à exploração de oportunidades, mas como também a satisfação das necessidades de uma forma criativa e inovadora. No cenário atual, a capacidade de empreender é o ponto inicial para a inovação, a introdução de melhorias no estilo de vida da sociedade moderna.
\end{abstract}

\section{Palavras-Chave: empreendedorismo, estrategias; educação empreendedora}

\section{RESUMEN}

El objetivo principal de este artículo fue discutir el emprendimiento a través de su aplicación en la educación. Se realizó una revisión de la literatura abordando los conceptos principales y la educación emprendedora y se discutió el impacto que puede generar a través de habilidades

\footnotetext{
1 Acadêmico em Licenciatura em química, IFPE-Campus Vitória de Santo Antão, E-mail; maxjefferson388@gmail.com

${ }^{2}$ Licenciatura em química, IFPE- Campus Vitoria de Santo Antão, larinanazario18@gmail.com

3 Tecnologia em Design Gráfico, IFPE, evertonmedeirosbezerra@gmail.com

${ }^{4}$ Professor, IFPE- Vitoria de Santo Antão, edisio.silva@vitoria.ifpe.edu.br

5 Professor, IFPE-Recife, erick.viana@recife.ifpe.edu.br
} 
a generar en el aula. La investigación desarrollada abordada. La educación emprendedora se propone estimular la formación crítica de los estudiantes motivados por los estudiantes. Desarrollando las mismas habilidades y abriendo caminos al mundo empresarial. la importancia de estudiar el emprendimiento va más allá de contar con estrategias orientadas a explorar oportunidades, sino también a satisfacer necesidades de forma creativa e innovadora. En el escenario actual, la capacidad de emprender es el punto de partida de la innovación, la introducción de mejoras en el estilo de vida de la sociedad moderna.

\section{PALABRA CLAVE: INVESTIGACION, INNOVACION, MEJORAS}

\section{ABSTRACT}

This article aimed to discuss entrepreneurship through its application in education. A literature review was carried out addressing the main concepts and entrepreneurial education and discussed the impact it can generate through skills to generate in the classroom. The developed research addressed. Entrepreneurial education proposes to stimulate critical training of students motivated by students. Developing the same skills and opening paths to the business world. The importance of studying entrepreneurship goes beyond having strategies aimed at exploring opportunities, but also meeting the needs in a creative and innovative way. In the current scenario, the ability to undertake is the starting point for innovation, the introduction of improvements in the lifestyle of modern society.

KEY WORDS: ENTREPRENEURSHIP, STRATEGIES; ENTREPRENEURIAL EDUCATION

\section{INTRODUÇÃO}

O Empreendedorismo faz-se incursões relevantes em áreas diversas do conhecimento humano como, comportamento pessoal e organizacional, recursos humanos, comunicação, ética, marketing. Estudar empreendedorismo na escola é, para além de se ter a oportunidade de conhecer o que é um Plano de Negócio, ele se relaciona ao desenvolvimento de competências com conhecimentos, habilidades e atitudes que permitem aos estudante aceitar a vivência de desafios com mensuração de riscos e ousar na resolução de problemas, sendo um percurso de grande significado para possibilitar o desenvolvimento do poder criativo natural do ser humano através da educação empreendedora.

A educação empreendedora tem um importante papel para o desenvolvimento de uma nação pois tem sido colocada como prioritária nas agendas e debates políticos, econômicos e acadêmicos no Brasil e em diversos países do mundo, sendo inserido nos mais altos níveis de discussão das Nações Unidas (UNCTAD, 2015; LIMA et. al.,2015a). A educação empreendedora também contribui para o aumento da qualidade da preparação e o número de jovens inovadores, proativos e com iniciativa, tanto para trabalharem em uma organização ou atividade autônoma, quanto para tocarem seu próprio negócio. 
Jones e English (2004) argumentam que o ensino de empreendedorismo se redireciona para o aprendizado de habilidades que podem ser ensinadas e comportamentos que devem ser desenvolvidos no indivíduo de forma a auxiliá-los na busca de novos e inovadores negócios.

Muitos desafios ainda existentes na educação empreendedora, como metodologias, práticas, treinamento de docentes e particularidades da temática, advém do fato do tema ser multidisciplinar e, muitas vezes complexo, influenciado pelos valores culturais do país quanto da aptidão de docentes e discentes (Lima et al., 2015). Isso faz com que a aprendizagem do empreendedorismo precise ser repensada (Hannon, 2006; Honig, 2004; Jones \& English, 2004;

Além disso Era \& Carswell, (2000), constatou-se que as universidades que se dedicam à promoção do empreendedorismo ainda estão focadas apenas na gestão empresarial e técnica, combinando-a com outras disciplinas (como psicologia, sociologia, educação, etc. E outros campos relacionados à compreensão do comportamento humano (LORENTZ, 2015). Assim, compreender a evolução das técnicas de ensino e conhecer seus fundamentos teóricos permite ao docente uma análise crítica sobre a metodologia utilizada, suas fragilidades e suas contribuições para os objetivos de aprendizado (McMULLAN \& LONG, 1987; RIDEOUT \& GRAY, 2013).

A educação empreendedora deve desenvolver as qualidades e habilidades necessárias a um empreendedor. De acordo com o consórcio para educação empreendera (2004) apud LOPES TEIXEIRA (2010), essa educação inclui as habilidades e conhecer habilidades de perseguir essas oportunidades, criar novas ideias e organizar os recursos necessários, e de pensar de forma criativa e critica. Dessa forma, essa pesquisa objetiva fazer uma breve revisão acerca do tema educação empreendedora e empreendedorismo presente na literatura acadêmica.

\section{FUNDAMENTAÇÃO TEÓRICA}

O empreendedorismo gera impactos na sociedade, na economia e na política, produzindo empregos, gerando rendas, proporcionando crescimento e desenvolvimento (ESPEJO e PREVIDELLI, 2006). Ademais, a origem do empreendedorismo está relacionada à teoria do capital humano e seus desdobramentos na educação e, na atualidade, os apelos para o empreendedorismo estão associados à crise do emprego formal causada pelo próprio capitalismo. 
Para Souza (2009), o “aprender a empreender” diminui o trabalho educativo à produção de mais-valia em contexto de crise estrutural, aproxima, dessa forma, a educação ao complexo da alienação. Isso porque ele tenta adaptar os indivíduos à sociedade capitalista de forma inábil, tentando em vão reconciliar o conflito entre capital e trabalho, ignorando o conteúdo desumano no processo de produção de mais-valor.

No Brasil, a educação empreendedora, na década de 1980, ganha adesão inicialmente no ensino superior, inserindo-se, aos poucos, para os outros níveis e modalidades de ensino. O ensino de empreendedorismo iniciou-se na Escola de Administração de Empresas da Fundação Getúlio Vargas, em São Paulo, em 1981. Em 1984, a Faculdade de Economia, Administração e Contabilidade da USP oferece a disciplina.

Segundo Araújo (2005), em 1993 foi criada uma rede de ensino de empreendedorismo através do programa SOFTEX/CNPq (Associação para Promoção da Excelência do Software Brasileiro) com o desenvolvimento de uma metodologia de ensino de empreendedorismo e atingiu mais de 100 departamentos de ensino de informática em 23 estados brasileiros e no Distrito Federal. (ARAÚJO et AL 2005).

A formação de jovens e trabalhadores empreendedores é uma proposta organicamente articulada ao projeto histórico do capital. Segundo Santos, empreendedorismo pode ser definido como: Movimento que introduz novos produtos e serviços, criando novas formas de organização ou explorando novos recursos e materiais. Argumenta-se que essa orientação, que promete realizar o sonho do sucesso pessoal e profissional, opera no sentido de naturalizar a condição de protagonista do jovem, único responsável por sua sobrevivência e pelo desenvolvimento econômico da coletividade a que pertence, revelando ser este um discurso pragmático e ideológico que reforça o individualismo característico da racionalidade neoliberal, o que permite apresentar as formulações que orbitam em torno da formação dos trabalhadores/empreendedores como ideologia.

Não podemos esquecer que o principal foco da educação empreendedora é, em última instância, contribuir para a geração de empregos e renda. Portanto, compreender o desenvolvimento da tecnologia educacional e compreender sua base teórica permite que os professores analisem criticamente os métodos usados, suas fraquezas e sua contribuição para os objetivos de aprendizagem (McMULLAN \& LONG, 1987; RIDEOUT \& GRAY, 2013).

\section{METODOLOGIA}


Esse trabalho se configura como abordagem de estudo feita através de pesquisa bibliográfica com uma revisão de literatura de autores que tratam dos temas empreendedorismo e educação empreendedora. Para atingir objetivo principal deste artigo foi discutido o empreendedorismo através de sua aplicação na educação. Foi realizada uma revisão de literatura e pesquisa bibliográfica abordando os principais conceitos e educação empreendedora e discutido o impacto que pode gerar por meio das habilidades estimuladas em sala de aula.

Conforme Salomon (2004), a pesquisa bibliográfica é procedimentos técnico fundamentado em conhecimentos proporcionados pela Biblioteconomia e Documentação, entre outras ciências e técnicas empregadas em métodos envolvendo a identificação, localização e obtenção da informação, fichamento e redação do trabalho científico. Todo esse processo requer planejamento de informações bibliográficas para elaboração e documentar um trabalho de pesquisa científica.

Segundo Gil (2009) a revisão de literatura dedica-se à contextualização do problema correlacionando com o tema investigado a seu respeito. Tem como finalidade esclarecimento dos pressupostos teóricos á que fundamentam à pesquisa e as contribuições levantadas por pesquisas anteriores. Ainda segundo Gil, essa revisão é constituída por sínteses de estudos, referências, e principalmente por discussão crítica do estudo abordado, que neste caso são empreendedorismo e a educação empreendedora.

\section{RESULTADOS E DISCUSSÃO}

O trabalho realizado buscou conhecer a percepção sobre a importância do empreendedorismo na vida acadêmica dos jovens que atualmente, percebe-se que a formação de alunos no Ensino Básico não é suficiente diante das dificuldades enfrentadas para ingressar no mercado de trabalho. A proposta de alfabetizar e realizar as instruções elementares, papéis tradicionais da Educação, não suprem necessidades futuras dos alunos. Entende-se que é necessária uma melhor preparação, tanto dos alunos quanto dos professores, no que se refere à atividade de ensino.

O trabalho em equipe é fundamentado na gestão democrática e na liderança participativa. Quando o profissional é inserido no mercado de trabalho, principalmente nos espaços educacionais, este precisa ter clareza de que não está atuando para si, nem mesmo sozinho. A educação tece relações interpessoais diárias. 
A formação de jovens e trabalhadores empreendedores é uma proposta organicamente articulada ao projeto histórico do capital. Argumenta-se que essa orientação, que promete realizar o sonho do sucesso pessoal e profissional, opera no sentido de naturalizar a condição de protagonista do jovem, único responsável por sua sobrevivência e pelo desenvolvimento econômico da coletividade a que pertence, revelando ser este um discurso pragmático e ideológico que reforça o individualismo característico da racionalidade neoliberal, o que permite apresentar as formulações que orbitam em torno da formação dos trabalhadores/empreendedores como ideologia.

Dolabela (2003) detalha quais tipos de habilidades devem ser trabalhadas na educação para o empreendedorismo, destacando a: criatividade; autonomia; comprometimento; liderança; alta tolerância a ambiguidades e incertezas; ousadia para assumir riscos; valorização da comunidade, e análise de contexto.

As habilidades empreendedoras devem ser trabalhadas tanto de forma segmentada como unificada. Dolabela (2003) sugere que o professor promova atividades específicas para o desenvolvimento de cada habilidade, mas concomitantemente, proporcione aos alunos situações onde todas as habilidades possam ser trabalhadas juntas, através, por exemplo, de feiras de exposições e vendas aos pais e responsáveis, onde os alunos precisarão ser criativos na escolha do produto ou serviço oferecido, além de estarem preparados para eventuais insucessos, trabalharem a autonomia e liderança na organização do ambiente, e desenvolverem suas habilidades financeiras, percebendo os frutos que a iniciativa empreendedora pode trazer.

A educação empreendedora propõe o estímulo a formação crítica dos estudantes motivados por discentes. Desenvolvendo nos mesmos habilidades e abrindo caminhos para mundo do negócio.

Oliveira e Barbosa (2014) ressaltam que o ensino do empreendedorismo requer diferentes abordagens, algumas das quais ainda sequer foram criadas. Porém, entendem que não basta apenas introduzir práticas ou propostas denominadas de “modernas”.

Segundo as autoras a educação empreendedora deve desenvolver habilidades de (LOPES; TEIXEIRA, 2010):

- reconhecer oportunidades;

- perseguir essas oportunidades, criar novas ideias e organizar os recursos necessários;

- criar e administrar um novo negócio ou projeto;

- pensar de forma criativa e de forma crítica. 
Também investigando as características a serem desenvolvidas, Becker (2014) defende que a educação empreendedora deve atentar a dois pontos importantes. O primeiro é que o aluno esteja apto a trabalhar com a criação, com o empreender e inovar.

O segundo é que ele esteja adaptado ao meio para que isso seja possível

”Ângelo (2003) dividiu os empreendedores de acordo com a motivação existente em adquirir um negócio próprio, para assim determinar se a iniciativa é resultado da percepção da oportunidade ou se há relação ao desemprego ou à falta de outras fontes de ganho, no caso uma necessidade. Deste modo o autor certifica que as taxas de empreendedorismo estão classificadas por necessidade e por oportunidade.

Empreendedorismo por oportunidade caracteriza-se para Shane e Venkataraman, (2000) em empresas que identificam e exploram oportunidades de mercado, Covin e Miles (1999) concordam e acrescentam que estes negócios renovam e rejuvenescem oportunidades.

A maioria dos negócios abertos por necessidade, de acordo com Aidar (2007), são por falta de oportunidade no mercado. Em 2002, novas micro pequenas empresas representavam 99,2\% das empresas formais no Brasil, empresas que surgem onde o ramo já está saturado, por ser facilitada a entrada no mercado, por necessitar menor valor de capital entre outros. Aidar (2007), afirma que isso afeta diretamente o equilíbrio do mercado, pois implicam em menores rendimentos e maiores concorrências, o que aumenta consideravelmente o risco de falência.

Aidar (2007) afirma que as oportunidades de negócios surgem de situações relacionadas a, novos conhecimentos, transformações tecnológicas, mudanças de preferências dos clientes, inconsistências deixadas pelo mercado. Para iniciar um negócio por oportunidade é imprescindível, que o empreendedor tenha conhecimento dos desafios a serem enfrentados, que trabalhe suas ideias antes de as transformarem em oportunidade de negócios, além de refletir sobre onde quer chegar, sobre seus conhecimentos e competências.

Dolabela (1999) está de acordo com o pensamento de Aidar (2007) quando afirma que a oportunidade tem algo de novo e atende a uma demanda dos clientes, representando um nicho de mercado, ou seja, aproveitando uma demanda de um segmento, produto ou serviço inexistente.

De acordo com o Conceito Nacional de Empresa Júnior a finalidade da empresa júnior é desenvolver profissionalmente os alunos por meio da vivência empresarial, realizando projetos e serviços na área de atuação do curso de graduação ao qual a empresa júnior for vinculada; realizar projetos e/ou serviços para micro e pequenas empresas, e terceiro setor, ou 
pessoas físicas, visando ao desenvolvimento da sociedade e; fomentar o empreendedorismo de seus associados. (BRASIL JÚNIOR, 2013).

O ecossistema empreendedor é composto por um conjunto de atores empresariais interligados, organizações empresariais (empresas, capital de risco, investidores anjos, bancos), instituições (universidades, órgãos do setor público, organismos financeiros) e processos empresariais que se juntam para se conectar, mediar e gerir o desempenho dentro do ambiente empresarial local (Mason, 2014).

Dentro deste contexto, as aceleradoras de empresas ajudam os empreendedores a definir e construir os seus produtos iniciais, identificar segmentos de clientes, e obter recursos incluindo capital e funcionários. Basicamente, elas desenvolvem programas de aceleração com duração limitada, geralmente com três meses, e ajudam as Startups com o processo do novo empreendimento, fornecendo uma pequena quantidade de capital, espaço de trabalho, oportunidades de networking e mentoria com empresários, advogados, pessoal técnico, investidores anjo, capital de risco, ou mesmo executivos de empresas. Finalmente, a maioria dos programas termina com um grande evento, denominado "Demo day", onde é realizada a apresentação do empreendimento para um grande público de investidores (Cohen, 2013). O ponto de equilíbrio de uma Startup ocorre quando a mesma consegue pagar suas contas com a receita do próprio negócio.

Segundo o SEBRAE, 2007, p. 2; Atualmente os empreendedores são reconhecidos como componentes essenciais para mobilizar capital, agregar valor aos recursos naturais, produzir bens e administrar os meios para administrar o comércio. Contudo, a educação empreendedora no Brasil teve início em 1981, na fundação Getúlio Vargas, lecionado pelo docente Ronald Degen, com o curso "Novos negócios - na especialização em Administração para Graduados. Desse modo, Drucker (1998) Não vê os empreendedores causando mudanças, mas vê os empreendedores explorando as oportunidades que as mudanças criam (na tecnologia, na preferência dos consumidores, nas normas sociais, etc). No entanto, a importância da educação empreendedora para o avanço de diversos países tem sido reconhecida, e a cada vez mais sendo utilizada pelas instituições.

Sob o ponto de vista de Dolabela (2003) O empreendedorismo não é um tema novo ou modismo: existe desde a primeira ação humana inovadora, com o objetivo de melhorar as relações do homem com os outros e com a natureza. Além disso, Dornelas (2003) enfatiza que, o empreendedorismo significa fazer algo novo, diferente, mudar a situação atual e buscar, de forma incessante, novas oportunidades de negócio, tendo como foco a inovação e a 
criação de valor. Contudo, a importância de se estudar o empreendedorismo vai além de se ter estratégias que visam à exploração de oportunidades, mas como também a satisfação das necessidades de uma forma criativa e inovadora.

Nesse contexto, ÂNGELO, 2003; Afirma que as taxas de empreendedorismos estão diretamente ligadas a duas vertentes: empreendedorismo por necessidade e por oportunidade, quando dividiu os empreendedores de acordo com a motivação existente em adquirir um negócio próprio, para assim determinar se a iniciativa é resultado da percepção da oportunidade ou se há relação ao desemprego ou à falta de outras fontes de ganho, no caso uma necessidade.

Segundo Aidar (2007) A maioria dos negócios abertos por necessidade, são por falta de oportunidade no mercado. Contudo, um dos fatores que também levam ao empreendedorismo por necessidade é queda de oportunidades de emprego em instituições, desse modo, o empreendedorismo por necessidade não é um termo recente e foi introduzido por Joseph Schumpeter em 1949, o empreendedor por necessidade não tem obrigação de criar algo novo, mas inova e coloca em prática, ele surge com transformações das relações de trabalho, ocorrendo uma reestruturação produtiva em busca do aumento da produtividade, consequentemente tem uma intensa integração dos mercados, crise fiscal dos estados nacionais e movimento de descentralização e horizontalização que impactaram sobre o mercado de trabalho, assim gerando uma quantidade significativa de trabalhadores que buscam formas alternativas de geração e manutenção do emprego e da renda familiar.

De acordo com Reynolds, Bygrave e Autio (2002) O empreendedor por oportunidade é capaz de escolher o empreendimento dentre as opções possíveis de carreira. Ademais, Aidar (2007) afirma que nem sempre as inovações vêm das ideias, mas das oportunidades. Desse modo, pode-se compreender o empreendedor como aquele que busca e explora a mudança como oportunidade, as oportunidade podem ser comparadas a atividades que exigem investimentos de recursos escassos acreditando no retorno futuro. Para se empreender por oportunidade é fundamental que se conheça os desafios a serem enfrentados, como também refletir onde quer chegar, bem como seus conhecimentos e suas competências.

Para Hisrich \& Peter (2004, p.33) o papel do empreendedorismo no desenvolvimento econômico envolve mais do que apenas o aumento de produção de renda per capita, envolve iniciar e construir mudanças na estrutura do negócio e sociedade. Contudo, o empreendedorismo tem impactos positivos na sociedade, a tabela a seguir apresenta as 
características das organizações empreendedoras com impacto social e as organizações empreendedoras sociais assistenciais.

\begin{tabular}{|c|c|}
\hline Empreendedorismo com Impacto Social & Empreendedorismo Social Assistencial \\
\hline Individual & Coletivo \\
\hline Produz bens e serviços & Produz bens e serviços à comunidade \\
\hline Foco no setor de mercado & Foco nas soluções dos problemas sociais \\
\hline A medida de desempenho não é só o lucro & Medida de desempenho é o impacto social \\
\hline Satisfazer as necessidades dos clientes & Respeitar as pessoas em risco social \\
\hline Ampliar a potencialidade do negócio & Promover os excluídos socialmente \\
\hline
\end{tabular}

Fonte: Adaptado de Melo Neto e Froes (2002)

Desse modo Leite (2000) ressalta que, o empreendedorismo é a criação de valor por pessoas e organizações trabalhando juntas para implementar uma idéia por meio da aplicação da criatividade, capacidade de transformar e o desejo de tomar aquilo que comumente se chamaria de risco. O Brasil tem um grande potencial empreendedor por oportunidades, esse tipo de educação busca inspirar alunos a vontade de empreender, porém, ainda é necessário fortalecer os modelos brasileiros de educação empreendedora, embora que no Brasil encontrase algumas iniciativas é fundamental enfatizar o fortalecimento da cultura empreendedora nacional e educação empreendedora, o programa de educação empreendedora contribui para a formação do profissional, adquirindo informações e conhecimentos para sua formação, o papel da instituição superior tem a importante missão de separar os profissionais para interagir e produzir mudanças em um ambiente de estabilidade. A universidade empreendedora tem como objetivo despertar o interesse para melhorias de um sistema de produção.

O conceito de "universidade empreendedora” se dá a partir de inovações, sendo este dependente de três vertentes: universidade - governo - empresa. Sob o ponto de vista do conhecimento de Etzkowitz (2006) uma universidade empreendedora pode converter os resultados de pesquisas de caráter comercial, em empresas inovadoras, com suporte das políticas de inovações. por outro lado, a universidade, governo e empresa para Mancini \& Lorenzo (2006) podem contribuir para que os participantes das pesquisas alcancem a excelência no seu resultado final. Da mesma forma que existe a troca de interesses entre si, buscando os benefícios de desenvolvimento, além disso, a relação entre universidade, governo e empresa realiza-se por consultorias individualmente de um professor a realizações de centros de pesquisas. O projeto de cooperação surge pela troca de serviços especializados, etc. 
O sistema de inovações é formado por várias organizações como: universidades e centros de pesquisa em empresas de consultorias, laboratórios de pesquisas, agências governamentais buscando a transferência de inovações. Nesse sentido, o governo tem por objetivo financiar, executar e regular o desenvolvimento científico de pesquisas e capacitações tecnológicas.

Para Chagas (2000) Não adianta mais acumularmos um estoque de conhecimentos. É preciso que saibamos aprender. Sozinhos e sempre. Como realizar o empreendedor na vida real: fazendo, errando, aprendendo. Ademais, o protagonismo educacional aborda como os estudantes são mais receptivos às mudanças educacionais no ensino superior e também estão mais favoráveis às inovações apresentadas a ele, então aderem com maior facilidade aos projetos proporcionados a ele, enquanto os docentes são mais cautelosos nessa questão da transformação educacional, para eles foi um momento desafiador, a aprendizagem em sala de aula por sua vez é o espaço para um ambiente de discussão e aprofundamento, o trabalho realizado em equipe pelo profissional, trazem significados na formação dos egressos da Instituição. No início desse modelo, as instituições perderam muitos alunos por não se adaptarem aos processos passivos apresentado a eles, então surgiram desafios para pensar e mudar o cenário em que se encontrava, essa implementação apresentou resultados positivos, em salas de aula o docente rompe as barreiras existentes e a metodologia ativa de aprendizagem torna-se motivo de defesa para permanência do modelo utilizado, isso ocorre devido a professores e alunos caminharem juntos. Esse método também dá autonomia ao estudante, expõe o aluno a prática e realização de atividades usando recursos de metodologia ativa centrada no modelo atual. O protagonismo só ocorre devido a participação efetiva dos estudantes propostas pelos docentes. Os estudantes se tornam protagonistas do seu processo participando das etapas, assim como se tornam interessantes os desafios apresentados a ele, fazendo sentido e se concentrando na prática.

De acordo com Hermanson (2011) Start up são as empresas de pequeno porte, recémcriadas ou ainda em fase de constituição, com atividades ligadas à pesquisa e desenvolvimento de idéias inovadoras, cujos custos de manutenção sejam baixos e ofereçam a possibilidade de rápida e consistente geração de lucros.

Dornelas (2003) Ressalta que o motivo do empreendedorismo ter se intensificado só agora, foi o avanço tecnológico que requer um número maior de empreendedores. O conceito está ligado a empresas em fase inicial, que apresenta uma ideia de negócio inovador e com um grande potencial de crescimento, podendo atuar em qualquer mercado e geralmente se utilizam de tecnologia para suas operações. 
Dornelas (2008, p.167) aborda os principais estágios de investimento de risco em empresas, desde sua concepção, são eles: 1- A fase inicial da ideia, que surge do próprio empreendedor, amigos, cônjuge, etc. 2- Quando a empresa já está construída, existindo a mais ou menos 1 ano e o produto está melhorando, sua aceitação está sendo analisada, nesta fase é muito difícil um investimento devido ao alto risco. 3- Essa é uma fase de expansão,conta com o desenvolvimento e precisa de mais capital, com a finalidade de um crescimento acelerado, em média de dois a três anos de existência. 4- A empresa busca uma maior expansão, negociando aquisições, parcerias e outros fundos de investimentos.

O ciclo de uma Startup pode ser representado pela figura 1, desde sua fase 1 até a 4, como citado por Dornelas (2008, p.167)

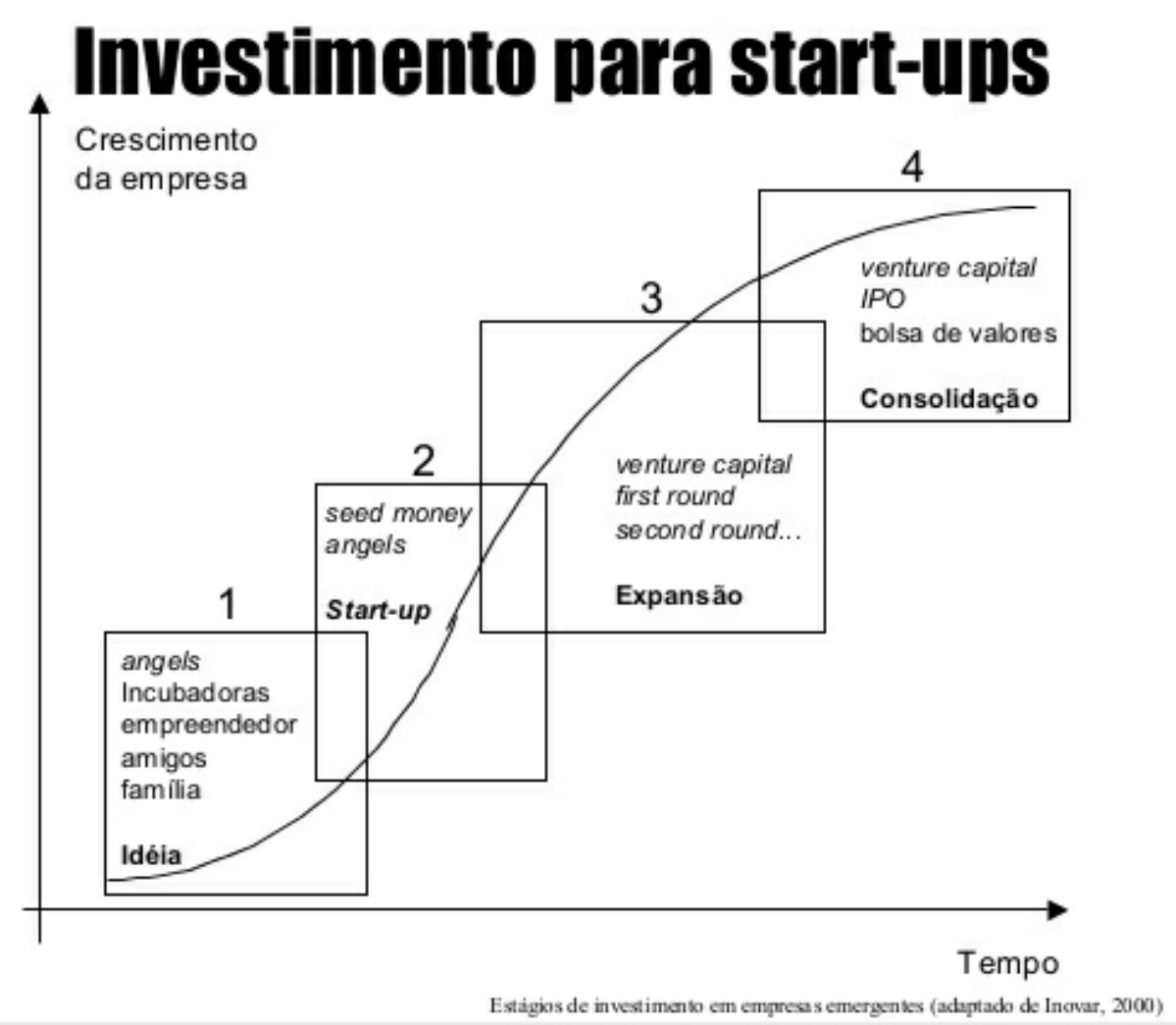

Fonte: www.empreende.com.br 


\section{CONCLUSÕES}

Perante o exposto, de acordo com o objetivo desse artigo em fazer uma breve revisão acerca do tema educação empreendedora e empreendedorismo presente na literatura concluise que o empreendedorismo tem muito a oferecer na vida dos jovens e adultos. E muitos professores sabem como alguns alunos de baixa renda tem o desejo de terminar o ensino médio pra ir trabalhar. $\mathrm{O}$ ensino do empreendedorismo deve desenvolver as qualidades e habilidades necessárias a um empreendedor, fazendo com que o mesmo cresça com o espírito empreendedor e também como pessoa e que se torne um empreendedor inovador e crítico.

Alguns autores declaram a organização da educação escolar dificultar no desenvolvimento de habilidades empreendedoras. Assim, a educação empreendedora deve ser planejada para empregar uma metodologia diferente da utilizada no ensino tradicional. Consequentemente, a postula do docente precisa ser diferente. Volta-se para o acompanhamento dos alunos em suas realizações, que perseguem na concretização dos seus sonhos.

A educação empreendedora deve ser planejada para empregar uma metodologia diferente da utilizada no ensino tradicional. Consequentemente, a postula do docente precisa ser diferente. Volta-se para o acompanhamento dos alunos em suas realizações, que perseguem na concretização dos seus sonhos

\section{REFERÊNCIA:}

AIDAR, M. M. Empreendedorismo: Coleção Debates em Administração. São Paulo: Thompson, 2007. 168p.

ANDRADE, A. F; TOROMAN, A. L. V; Fatores de influências na estruturação de programas de educação empreendedoras em instituições de ensino superior; ANAIS DO II EGEPE, p. 299-311, Londrina/PR, Novembro/2001 (ISSN 1518-4382)

ÂNGELO, E. B. Empreendedor Coorporativo: a nova postura de quem faz a diferença. Rio de Janeiro: Elsevier, 2003. 250p

BRASIL JÚNIOR. Confederação Brasileira de Empresas Juniores. Disponível em: .Acesso em: 08 nov. 2013.

COHEN, S. What Do Accelerators Do? Insights from Incubators and Angels, 2013

FAVA, R. Educação para o século XXI: a era do indivíduo digital. São Paulo: Saraiva, 2016. 
FOWLER, F.R. Programas de Desenvolvimento de Empreendedorismo - PDEs. Um estudo de casos: FEA-USP e DUBS. São Paulo: FEAC, 1997. 101f. Dissertação (Mestrado em Administração) - Faculdade de Economia, Administração e Contabilidade da Universidade de São Paulo, 1997.

GIL, A. C. Como elaborar um projeto de pesquisa. São Paulo: Atlas, 2009

KRAUKER, P. V. D; SANTOS, S. A; ALMEIDA, M. I. R Teoria da aprendizagem experencial no ensino médio de empreendedorismo: Um estudo exploratório. REGEPE, São Paulo, v.6, n.1, p. 101-127; Jan/abri. 2017

LOPES, R. M. A.; TEIXEIRA, M. A. A. Educação empreendedora no ensino fundamental. In: LOPES, R. M. A. (Org.). Educação empreendedora: conceitos, modelos e práticas. Rio de Janeiro: Elsevier: São Paulo: SEBRAE, 2010.

MASON, C.; BROWN, R.; Entrepreneurial Ecosystems and Growth Oriented Entrepreneurship, 2014.

OLIVEIRA, P. S. FONSECA, R. M. S. A educação para o empreendedorismo: tecendo um novo sentido ao processo educativo. Revista Científica Multidisciplinar Núcleo do Conhecimento. Ano 03, Ed. 10, Vol. 01, pp. 63-81 Outubro de 2018.

SALOMON, D. V. Como fazer uma monografia. Martins Fontes, 2004

Schaefer, R.; Minello, I. F.

EDUCAÇÃO EMPREENDEDORA: PREMISSAS, OBJETIVOS E METODOLOGIAS

Revista Pensamento Contemporâneo em Administração, vol. 10, núm. 3, julio-septiembre, 2016, pp. 60-81

SCHANE, S.; VENKATARAMAN, S. The Promise of Entrepreneurship as a Fiel of Research. The Academy of Management Review. v.25, n.1, p.217-227, 2000.

SIGUAW, J.A.; SIMPSON, P.M; ENZ, C.A. Conceptualizing innovation rientation: a framework for study and integration of innovation research. Entrepreneurship Theory and Practice, v.23, n.6, p 556-574, 2006

SOUZA, J. S. Trabalho, qualificação, ciência e tecnologia no mundo contemporâneo: fundamentos teóricos para uma análise da política de educação profissional. Educação e Contemporaneidade, Salvador, v. 13, no 22, p. 1-15, ju./dez. 2004. 